Chirurgia (2018) 113: 399-404

No. 3, May - June

Copyright@ Celsius

http://dx.doi.org/10.21614/chirurgia.113.3.399

\title{
Evaluation of P-POSSUM Risk Scoring System in Prediction of Morbidity and Mortality after Pancreaticoduodenectomy
}

\author{
Raluca Bodea', Nadim Al Hajjar', Adrian Bartos², Florin Zaharie', Florin Graur', Cornel lancu' \\ "'luliu Hatieganu” University of Medicine and Pharmacy Cluj, Surgical Clinic no. 3 Cluj, Romania \\ ${ }^{2}$ Surgical Clinic no. 3 Cluj, Romania
}

Corresponding author:

Professor Nadim Al Hajiar

Surgical Clinic No. 3, IRGH Cluj

19-23 Croitorilor Street, Cluj-Napoca

E-mail: na_hajjar@yahoo.com

\section{Abbreviations:}

PD: Pancreaticoduodenectomy; ERAS: Enhanced Recovery After Surgery;

PVR: Portal Vein Resection;

POPF: Postoperative Pancreatic Fistula;

DGE: Delay Gastric Emptying;

PPH: Postpancreatectomy Hemorrhage;

\section{Rezumat}

Evaluarea scorului P-POSSUM în predicția morbidității și a mortalității după duodenopancreatectomia cefalică

Introducere: Societatea ERAS (Enhanced Recovery After Surgery) recomandă folosirea scorurilor POSSUM şi P-POSSUM în chirurgia abdominală majoră, pentru estimarea riscului de apariție a complicațiilor şi a decesului postoperator.

Material şi metodă: Studiul include 113 duodenopancreatectomii cefalice consecutive efectuate într-un singur centru în perioada iulie 2013-decembrie 2015. Datele pacienților au fost introduse prospectiv într-o bază de date şi ulterior analizate utilizând $\mathrm{R}$ v3.2.4 software. Scorul statusului biologic, scorul operator şi scorurile asociate morbiditătii şi mortalitătii au fost calculate accesând http://www.riskprediction.org.uk/index-pp.php.

Rezultate: Rata de apariție a complicațiilor a fost de $61,95 \%$ : $19,47 \%$ complicații generale, $14,16 \%$ supurații de plagă şi $28,32 \%$ complicații specifice duodenopancreatectomiei cefalice $(11,5 \%$ fistule pancreatice; 8,85\% evacuare gastrică întârziată şi 6,19\% hemoragii). Comparând morbiditatea şi mortalitatea observate cu cele estimate de scorul P-POSSUM, am obținut diferențe statistic semnificative ( $p=0,05$ şi $p=0,03)$. Aceste diferențe nu au mai existat dacă am comparat complicațiile specifice duodenopancreatectomiei cefalice şi mortalitatea consecutivă lor, cu cele estimate de scor $(p=0,8$, respectiv $p=0,86)$. Aria de sub curbă a avut valori de 0,61 pentru morbiditate, 0,64 pentru morbiditatea specifică operației, respectiv 0,61 pentru mortalitate şi 0,68 pentru mortalitatea consecutivă complicaților specifice.

Concluzie: P-POSSUM este un instrument util, dar nu suficient, de 
apreciere a riscului de complicații şi deces după duodenopancreatectomia cefalică. Rezultate mai bune pot fi obținute dacă analizei i se asociază şi factorii de risc specifici intervenției.

Cuvinte cheie: duodenopancreatectomie cefalică, scor P-POSSUM, morbiditate postoperatorie, mortalitate

\begin{abstract}
Background: POSSUM and P-POSSUM are risk scores recommended by ERAS Society for the preoperative evaluation of patients undergoing major surgery.

Methods: This study includes 113 consecutive pancreaticoduodenectomy performed in a single centre between July 2013-December 2015. Patients data were prospectively collected using Excel 2009 and retrospectively analysed with R v3.2.4 software. Biological status score, surgical severity score and risk scores for complications and death were calculated using: http://www.riskprediction.org.uk/index-pp.php.

Results: Morbidity rate was 61,95\%: 19,47\% general complications, $14,16 \%$ wound infections and 28,32\% PD specific complications (11,5\% POPF; 8,85\% DGE and 6,19\% PPH). Comparing the observed and estimated morbidity and mortality, we obtained statistical significant results $(\mathrm{p}=0,05$ and $\mathrm{p}=0,03$, respectivelly). When we considered only specific PD complications and subsequent mortality, there was no longer significant difference between observed and estimated values $(\mathrm{p}=0,8$ and $\mathrm{p}=0,86$ ). The under ROC curve aria was 0,61 for morbidity and 0,64 for specific PD morbidity, respectively 0,61 for mortality and 0,68 for specific PD complications related mortality.

Conclusion: P-POSSUM represents a useful tool for appreciating the complication and death risk after PD, but better results could be obtain by considering also specific PD risk factors.
\end{abstract}

Key words: cephalic pancreaticoduodenectomy, P-POSSUM score, postoperative morbidity, mortality

\section{Introduction}

During preoperative morbidity and mortality evaluation of the patient for a major surgery, risk scores can be used due to their ability to offer numeric or percentage results, which may allow an objective evaluation of risks and a fair discussion with the patient himself or his family. For pancreaticoduodenectomy (PD), we can find several risk scores, proposed by different surgical centres, one of them being P-POSSUM score, recommended by ERAS (Enhanced Recovery After Surgery) Society. Both POSSUM and P-POSSUM are risk prediction tools for complications or postoperative deaths, based on patient biological status and surgical severity scores. Due to some authors observation that POSSUM overestimates mortality, Whitley (1), using logical regression, modified mortality risk formula, so coming into existence P-POSSUM risk score. For biological status score, both POSSUM and P-POSSUM take into consideration twelve parameters (age, cardiac, respiratory, ECG, systolic BP, pulse rate, haemoglobin, leucocytes, urea, sodium, potassium, Glassgow score) and for surgical severity score, six parameters (operation type, number of procedures, operative blood loss, peritoneal contamination, malignancy status, elective/urgent surgery).

\section{Objectives}

The aim of this study is to evaluate the capacity of P-POSSUM risk scores concerning the morbidity and mortality following standard 
pancreaticoduodenectomy and pancreaticoduodenectomy associated with portal vein resection (PVR-PD).Validation of the score enables afterwards a preoperative identification of risk patients and prevents the risk of undesirable consequences by both preparing the patient properly before the procedure and a closer postoperative monitoring.

\section{Material and Methods}

In this study we included 113 consecutive pancreaticoduodenectomy performed for periampullary malignant tumors in Surgical Clinic no. 3 Cluj Romania, during July 2013December 2015. Demographic, clinical, imaging and operative data were prospectively collected in a database and retrospectively analysed.

Biological status score, surgical severity score as well as risk scores for complications and death were calculated using online link address: http://www.riskpredictionorg.uk/ indexpp.php. We considered standard PD as "major operation", but it became a "complex major operation" if portal vein resection was added. Also, to "number of procedures" parameter we fill in: "one " if we performed only the PD, or "two", if PD was preceded by biliary drainage. All surgeries were elective.

For postoperative pancreatic fistula (POPF) we used the International Study Group for Pancreatic Fistula definition (2), including three degrees: A- no clinical impact, just high amylase level in a drainage tube; $\mathrm{B}$ - high amylase level in a drainage tube and clinical symptoms, or need for drainage maintenance for more than three weeks, or endoscopic/imagistic drainage of an intraabdominal collection; $\mathrm{C}^{-}$hemodynamic instability and need for reoperation. Delay gastric emptying (DGE) (3) is the patient incapacity for resuming oral feeding by the $7^{\text {th }}$ postoperative day due to important gastric stasis, imposing prolonged nasogastric tube maintenance. It has also three degrees: A-maintaining the nasogastric tube for more than seven days or reinsertion of the tube after $4^{\text {th }}$ postoperative day, with or without nausea or vomiting or prokinetics; B-maintaining the nasogastric tube for 8-14 days or reinsertion the tube after postoperative day 7 , with vomiting and prokinetics, the patient being unable to eat the first 14 days; $\mathrm{C}^{-}$maintaining the nasogastric tube for more than 14 days or reinsertion of the tube after postoperative day 14, with vomiting and prokinetics, the patient being unable to eat for the first 21 days. For postpancreatectomy hemorrhage $(\mathrm{PPH})$ we used the International Study Group of Pancreatic Surgery definition (4), which recognize three categories: mild, moderate and severe. Mild hemorrhage means a haemoglobin loss under $1,5 \mathrm{~g} / \mathrm{dl}$, which stops spontaneously, without needing blood transfusion. Moderate hemorrhage refers to a haemoglobin loss between 1,5-3 g/dl, with minor hemodynamic impact, which don't need endoscopic or surgical intervention. A severe bleeding involves a haemoglobin loss more than $3 \mathrm{~g} / \mathrm{dl}$, which dictate an endoscopic or surgical approach. We consider as general complications: respiratory (broncho-pulmonary infections or inflammations, pleurisy, respiratory insufficiency), circulatory (cerebrovascular stroke, myocardial ischemia, cardiac failure), hepatic (hepatic failure) or renal ones (acute renal failure).

The data were collected using Excel 2009 and the statistical analysis was done with $R$ v3.2.4 software. Kolomogorov-Smirnov test was the first step in analysis. For continuous data we used T-tests and the results were reported as median \pm standard deviation. For nominal data we used chi-square test and the results were presented as frequencies. The $p<0,05$ values were considered statistically significant.

\section{Results}

This study involved 113 patients, including 64 males $(56,64 \%)$ and 49 females $(43,36 \%)$, age between $22-81$ (median of 64 ).

Morbidity rate was $61,95 \%: 19,47 \%$ general complications, $14,16 \%$ wound infections and $28,32 \%$ PD specific complications. Pancreatic fistula had a 11,5\% incidence (two cases grad A, four cases grad B and seven cases grad C). 
Table 1. Complications following pancreaticoduodenectomy

\begin{tabular}{lcc}
\hline Type & PD & PVR-PD \\
\hline POPF & $11 / 103(9,73 \%)$ & $2 / 10(20 \%)$ \\
\hline Billiary fistula & $1 / 103(0,97 \%)$ & $0 / 10$ \\
\hline Digestive fistula & $1 / 103(0,97 \%)$ & $0 / 10$ \\
\hline Pancreatic stump hemmorhage & $6 / 103(5,82 \%)$ & $0 / 10$ \\
\hline Intraabdominal hemmorhage & $1 / 103(0,97 \%)$ & $0 / 10$ \\
\hline DGE & $8 / 103(7,77 \%)$ & $2 / 10(20 \%)$ \\
\hline General complications & $19 / 103(18,45 \%)$ & $3 / 10(30 \%)$ \\
\hline Total & $47 / 103(45,63 \%)$ & $7 / 10(70 \%)$ \\
\hline Mortality & $6 / 103(5,83 \%)$ & $2 / 10(20 \%)$ \\
\hline
\end{tabular}

Delay gastric emptying, without following a fistula, appeared in ten patients $(8,85 \%)$, none needing relaparotomy. Postpancreatectomy hemorrhage was manifested in seven patients $(6,19 \%)$ (six with upper digestive hemorrhage from intragastric pancreatic stump and one with intraperitoneal hemorrhage), relaparotomy being mandatory for two patients with upper digestive hemorrhage and for the patient with intraperitoneal hemorrhage. There was one external biliary fistula which spontaneously healed and one gastro-jejunal anastomotic fistula, which needed relaparotomy. Table 1 include patients complications.

Totally, there were eleven relaparotomies $(9,7 \%)$, three deaths $(2,65 \%)$ following general complications and five deaths $(4,24 \%)$ following specific PD complications (five pancreatic fistulas, one pancreatic stump hemorrhage and one intraperitoneal hemorrhage).

It should be noticed that the more frequent rate of pancreatic fistula and gastric stasis occur in portal vein resection group, without being able to achieve statistical significance, due to the reduced number of cases.

Both biological status and surgical severity scores, and morbidity and mortality risk scores for the all the patients can be found in Table 2.

There is no statistical difference between patients with standard PD and those with portal resection PD regarding biological status score. Also, adding portal vein resection to standard PD did not increased the estimated risk for complications (31,7\% versus $40 \%$, $\mathrm{p}=0,75$ ). Instead, having more cases with
Table 2. P-POSSUM values

\begin{tabular}{lccc}
\hline & PD & PVR-PD & p \\
\hline Biological status score & $19,15 \pm 4,98$ & $17 \pm 4,52$ & 0,97 \\
\hline Surgical severity score & $15,5 \pm 4,23$ & $27,3 \pm 2,63$ & 0,03 \\
\hline Morbidity & 31,7 & 40 & 0,75 \\
\hline Mortality & 4,53 & 16,4 & 0,002 \\
\hline
\end{tabular}

Table 3. Validation of P-POSSUM score considering all complications

\begin{tabular}{lccc}
\hline & PD (103) & PVR-PD (10) & TOTAL (113) \\
\hline O Morb/E Morb & 1,44 & 1,75 & 1,66 \\
\hline 0 Mort/E Mort & 1,29 & 1,22 & 0,69 \\
\hline O
\end{tabular}

0 Morb=observed morbidity; E Morb=estimated morbidity;

0 Mort=observed mortality; E Mort=estimated mortality

Table 4. Validation of P-POSSUM score considering PD specific complications

\begin{tabular}{lccc}
\hline & PD (103) & PVR-PD (10) & TOTAL (113) \\
\hline O Morb/E Morb & 0,86 & 1,0 & 0,89 \\
\hline O Mort/E Mort & 0,86 & 0,61 & 0,72 \\
\hline 0 Morb=observed morbidity; E Morb=estimated morbidity; \\
O Mort=observed mortality; E Mort=estimated mortality
\end{tabular}

intraoperative of over $500 \mathrm{ml}$ blood loss cases and due to superior score granted to portal vein resection $P D$, we obtained significant increase of operative score (from 15,5 $\pm 4,23$ to $27,3 \pm 2,63, p=0,03)$, with mortality increased 3,5 times.

In order to determine the value of P-POSSUM score in evaluating postoperative complications and death, we compared the observed values for morbidity and mortality with the estimated ones. The results of this comparation can be found in Table 3 and Table 4.

First, we noticed that the predictive power of P-POSSUM score was higher in PD specific complications and subsequent mortality com- $^{-}$ pared to the whole morbidity and mortality rates.

When to specific complications, wound infections and general complications occur, the score underestimates risk. If we take into consideration only PD specific complications, P-POSSUM overestimates it.

Comparing the observed morbidity and estimated morbidity, we obtained statistical significant results $(61,95 \%$ versus $37,2 \%$; 
$\mathrm{p}=0,03)$. The same situation appeared when evaluating the observed mortality and estimated mortality $(7,08 \%$ versus $12,9 \% ; p=0,05)$.

However, when we considered only specific PD complications and subsequent mortality, there was no longer significant difference between observed and estimated values ( $28,32 \%$ versus $33,1 \% ; p=0,8$ for morbidity and $4,24 \%$ versus $5,6 \% ; p=0,86$ for mortality).

To validate or invalidate P-POSSUM score in assessing risk after PD, we used ROC curves. The results showed that under ROC curve aria was 0,61 for morbidity and 0,64 for specific PD morbidity, respectively 0,61 for mortality and 0,68 for specific $\mathrm{PD}$ complications related mortality.

We tried to find a cut-off, a point from which the test accomplished good predictive value and we chose the biological status score of 18. For morbidity, the results were: sensibility 0.65 [CI95\% (0.562, 0.735)] and specificity 0.5 [CI95\% (0.388, 0.606)], under ROC curve aria being 0,63 . For PD specific morbidity, sensibility was 0.733 [CI95\% $(0.611,0.837)$, specificity was 0.515 [CI95\% $(0.434,0.583)]$ and under ROC curve aria was 0,7 .

\section{Discussions}

P-POSSUM score involves parameters regarding biological status of the patient and intraoperative aspects. Of those, only few were unanimously recognised as risk factors for pancreaticoduodenectomy complications: anaemia, leucocytosis and intraoperative blood loss. But, the P-POSSUM does not consider some wellestablished risk factors, as pancreatic texture, Wirsung diameter, pancreatic stump anastomosis, surgical expertise. An important fact regarding $\mathrm{PD}$ is that despite significant decreasing of mortality rates in pancreatic tertiary centres (under $5 \%)(5,6,7)$, morbidity remains high and constant, being considered one of the most important postoperative care indicators (8).

Our first result indicates a significantly difference between surgical severity scores $(p=0,03)$ and mortality scores $(p=0,002)$ between patients with portal vein resection $\mathrm{PD}$ and those with standard PD. The difference is due to more cases with blood loss over $500 \mathrm{ml}$ in portal vein resection $\mathrm{PD}$ group and a superior score granted for a "complex major operation", as venous resection PD was classified. The result, "ad litteram" seen, indicates that the venous resection is a risky moment. Actually, in all cases, the vein resections were tangentially and prepared by the surgeon, without significant blood loss. Confronting those data, we decided, further on, to evaluate the score including all patients in one group, trying to avoid errors. Same kind of errors were reported by Tamijmarane (9), who recommends that standard PD and portal vein resection PD to be consider either "major operation" or "complex major operation".

Ratio between observed and estimated morbidity was 1,66 , meaning that the score underestimates morbidity risk. However, an important percentage, over 50\%, was represented by wound infections and temporary organ failure immediately after surgery. Excluding those, the ratio became subunitary and close to $1(0,89)$.

The fact that P-POSSUM is more valuable in predicting specific complications after $\mathrm{PD}$ is also indicated by the significant difference between observed and estimated morbidity when all complications are considered $(p=0,03)$, difference which is no longer statistically significant when only specific complications are analysed $(\mathrm{p}=0,8)$.

Regarding mortality, P-POSSUM overestimates death risk both when all complications were analysed $(0,69)$ and when only specific ones were evaluated $(0,72)$.

For assessing P-POSSUM efficiency in estimating morbidity and mortality risks, we calculate under ROC curve aria. For morbidity and PD specific morbidity, the aria was 0,61 and 0,64 , respectively. For mortality and PD specific complications related mortality, the under ROC curve aria was 0,61 and 0,68, respectively. These results may be interpreted as "fair", which indicates that the P-POSSUM score may be used as prediction tool for PD morbidity and mortality, but not alone.

We tried to determine some conditions which, once obtained, are capable to offer 
valuable results for risk prediction. We chose biological status score, the less liable to bias, due to the fact that, from all twelve parameters involved in this score formula, only one, meaning "ECG" is subjective (10). From 18 upwards of the biological status score value, under ROC curve aria is 0,63 for all complications and 0,7, meaning "good", for PD specific morbidity.

Reviewing the literature, after the first studies enthusiasm $(11,12)$, beginning with 2013 there are publications whose authors are more reserved, admitting though that P-POSSUM can be used, but in addition to the recognised PD risk factors $(13,14,15)$ and some more studies with larger study on patients are needed $(9,16)$.

\section{Conclusions}

P-POSSUM represents a useful tool, but not complete, for appreciating the complication risk or death risk after PD. The importance of the information P-POSSUM gives may become relevant weather it takes into consideration a larger number of patients, cut-offs that provide sensibility, specificity and graphic connection between them (under ROC curve aria) become statistically significant. The cut-off should include the least subjective score, namely the biological status score. Early prediction of some specific risk factors for the patient scheduled for a PD may be more valuable information.

Conflict of Interest: none declared.

\section{References}

1. Whiteley MS, Prytherch DR, Higgins B, Weaver PC, Prout WG. An evaluation of the POSSUM surgical scoring system. Br J Surg.
1996;83:812-5

2. Bassi C, Dervenis C, Butturini G, et al. International Study Group on pancreatic fistula definition. Postoperative pancreatic fistula: an international study group (ISGPF) definition. Surgery 2005:138:8-13

3. Wente MN, Bassi C, Dervenis C, et al. Delayed gastric emptying (DGE) after pancreatic surgery: a suggested definition by the International Study Group of Pancreatic Surgery (ISGPS). Surgery. 2007;142(5):761-8

4. Wente M. N., Veit J. A., Bassi C., et al. Postpancreatectomy hemorrhage (PPH): an International Study Group of Pancreatic Surgery (ISGPS) definition. Surgery. 2007;142(1):20-25

5. McMillan MT, Vollmer CM Jr, Asbun HJ, et al. The Characterization and Prediction of ISGPF Grade C Fistulas Following Pancreatoduodenectomy. J Gastrointest Surg. 2016;20:262-76.

6. Hackert T, Hinz U, Pausch T, et al. Postoperative pancreatic fistula: We need to redefine grades B and C. Surgery. 2016;159:872-7

7. Kimura W, Miyata H, Gotoh M, et al. A pancreaticoduodenectomy risk model derived from 8575 cases from a national single-race population (Japanese) using a web-based data entry system the 30-day and in-hospital mortality rates for pancreaticoduodenectomy. Ann Surg. 2014:259:773-80

8. Khan AW, Shah SR, Agarwal AK, Davidson BR. Evaluation of the POSSUM scoring system for comparative audit in pancreatic surgery. Dig Surg. 2003;20:539-45.

9. Tamijmarane A, Bhati CS, Mirza DF, et al. Application of Portsmouth modification of physiological and operative severity scoring system for enumeration of morbidity and mortality (P-POSSUM) in pancreatic surgery. World J Surg Oncol. 2008; 6: 39

10. Neary WD, Heather BP, Earnshaw JJ. The Physiological and Operative Severity Score for the enUmeration of Mortality and morbidity (POSSUM) Br J Surg. 2003;90:157-65

11. Richards $C$, Leitch F, Horgan P. McMillan D. A systematic review of POSSUM and its related models as predictors of post-operative mortality and morbidity in patients undergoing surgery for colorectal cancer. J Gastrointest Surg. 2010;14(10):1511-20

12. Khan AW, Shah SR, Agarwal AK, Davidson BR. Evaluation of the POSSUM scoring system for comparative audit in pancreatic surgery. Dig Surg. 2003;20(6):539-45

13. Chen Y, Chu Y, Che X, Lan Z, Zhang J, Wang C. Value of PUSSOM and P-POSSUM for the prediction of surgical operative risk in patients undergoing pancreaticoduodenectomy for periampullary tumors. Zhonghua Zhong Liu Za Zhi. 2015;37(6):461-5

14. Haga Y, Wada Y, Saitoh T, Takeuchi H, Ikejiri K, Ikenaga M. Value of general surgical risk models for predicting postoperative morbidity and mortality in pancreatic resections for pancreatobiliary carcinomas. J Hepatobiliary Pancreat Sci. 2014;21(8):599-606

15. Zhong J, Zhao L, Zhou W, Li L, Shi X. Significance of the POSSUM scoring system in predicting morbidity and mortality in elderly patients after pancreatoduodenectomy. Hepatogastroenterology. 2013;60(125):1211-6.

16. Chen T, Wang H, Wang H, Song Y, Li X, Wang J. POSSUM and PPOSSUM as predictors of postoperative morbidity and mortality in patients undergoing hepato-biliary-pancreatic surgery: a metaanalysis. Ann Surg Oncol. 2013 Aug;20(8):2501-10 